\section{Life expectancy among elderly Brazilians in 2003 according to different levels of functional disability}

\author{
Expectativa de vida para idosos brasileiros em \\ 2003, segundo diferentes níveis de \\ incapacidade funcional
}

\author{
${ }^{1}$ Centro de Desenvolvimento \\ e Planejamento Regional, \\ Universidade Federal de \\ Minas Gerais, Belo Horizonte, \\ Brasil. \\ Correspondence \\ C. J. Machado \\ Departamento de \\ Demografia, Centro \\ de Desenvolvimento e \\ Planejamento Regional, \\ Universidade Federal de \\ Minas Gerais. \\ Av. Augusto de Lima 1376, \\ sala 908, Belo Horizonte, $M G$ \\ 30190-003, Brasil. \\ cjmachado@terra.com.br
}

\begin{abstract}
The aim of the present study was to estimate disability-free life expectancy for the Brazilian elderly in 2003, by gender and age, based on different concepts of functional disability. The Sullivan method is used to combine the period life tables from the Brazilian Institute of Geography and Statistics (IBGE, 2003) and the prevalence of functional disability according to the $2003 \mathrm{Na}$ tional Sample Household Survey (PNAD 2003). The main results of the study indicate that at age 60 , Brazilian men can expect to live 19 years, $39 \%$ with mild, 21\% with moderate, and 14\% with severe functional disability, respectively. At the same age, Brazilian women can expect to live 22 years: $56 \%$ with mild, $32 \%$ with moderate, and $18 \%$ with severe functional disability.
\end{abstract}

Aged; Active Life Expectancy; Frail Elderly
Mirela Castro Santos Camargos 1

Carla Jorge Machado 1

Roberto Nascimento Rodrigues 1

\section{Introduction}

The elderly population is growing at a faster rate than the overall population and people are living longer. Therefore, there is an increasing interest in investigating whether the years added to life expectancy for these elderly are lived in adequate health conditions.

Classic indicators such as cause-specific mortality rates and morbidity indicators (disease prevalence) become insufficient to evaluate the well-being, health status, and service needs of the elderly population. In the case of mortality rates, for example, they do not always accurately reflect the health or morbidity situation, especially in the case of the elderly, since many causes of death have low case-fatality rates, and thus underestimating their real importance for the overall population. In addition, when one analyzes underlying causes of death, the most common model for analyzing mortality by causes 1 , one does not consider the multiple concurrent disease conditions (associated causes), which also means that the real causal structure of morbidity and mortality is not known. Meanwhile, when prevalence indicators are used to focus on the surviving population, the problem results from the fact that such indicators cannot adequate reflect the case-fatality of diseases. Thus, there may be diseases with high case fatality and mortality, but very low prevalence (e.g., cholera) and vice versa (e.g., diabetes). 
It would be extremely useful to have an indicator that combined mortality and the population's health status. Estimates of healthy life expectancy have been used to meet the demand for information on the amount of years lived with health. The notion of healthy life expectancy is similar to that of total life expectancy, but refers to the mean number of years that someone of a given age can expect to live with health, given that the morbidity and mortality rates prevail for that specific age. Thus, total life expectancy consists of the amount of years lived (from birth or a given age onward) in different states of health, until death, where the years lived with health provide the healthy life expectancy 2 .

Just as there are various definitions for health, there are different ways of measuring healthy life expectancy, such self-perceived health, the consequence of diseases, functional disability, and the notion of physical, mental, or social well-being ${ }^{3}$. Therefore, the way health is operationalized depends on the researcher's objectives and the available data. Different ways of measuring health status can also lead to different results for healthy life expectancy. In practice, healthy life expectancy is often estimated as life expectancy free of functional disability ${ }^{4}$, i.e., free of difficulty in performing given activities.

The importance of studying functional status lies in the fact that this indicator correlates with the feeling of individual well-being, predicts health and consumption of social services, and has a positive or negative impact on the family 5 . Functional capacity emerges as a new concept of health, particularly important within the new health paradigm raised by population aging. From this new perspective, what matters is not diseases themselves, but individuals' capacity to maintain themselves in the community, enjoying their independence and maintaining their social relations and activities 6 .

In the specific case of Brazil, where the current population aging process creates new demands on the health sector, the estimation of life expectancy free of functional disability can aid the planning of public policies, pointing to some of the real needs of the elderly population and allowing adequate allocation of human and financial resources. After all, this health indicator provides information not only on the prevalence of functional disability, but also on the potential duration of disability and the time demanded for personal care for part of the population 7 .

In Brazil, some recent studies have estimated healthy life expectancy 8,9,10,11. However, there is still a scarcity of Brazilian studies in this area, which can be partially attributed to the lack of information, such as that pertaining to functional disability. The way functional disability is measured can vary between different studies.

The objective of this study was to measure life expectancy free of functional disability in the Brazilian elderly, by sex and age, for the year 2003, using different levels of functional disability. In this case, functional disability was measured in three different ways according to the degree of severity, estimating the number and proportion of years of life with mild, moderate, and severe disability, in addition to the years of life free of these conditions, as well as their proportions.

\section{Data source and methodology}

\section{Data and operationalization}

Functional disability prevalences were estimated based on data from the 2003 National Sample Household Survey (PNAD) 12, which contains a special health module. The survey covers the entire country, with the exception of the rural area of the States of Rondônia, Acre, Amazonas, Roraima, Pará, and Amapá. The sample included persons 60 years or older and excluding those who failed to state their age (72 cases). The total sample was thus 35,042 .

Activities of daily living, instrumental activities of daily living, and mobility are the most frequently used measures to evaluate individual functional disability, and are considered important indicators of health status in the elderly 7,13 . Activities of daily living include simple tasks related to personal care. Instrumental activities of daily living are linked to complex activities, related to the person and the environment in which he or she lives. Meanwhile, mobility can be measured as the capacity to perform simple tasks, such as getting from bed to a chair, proceeding to more complex tasks, like short and long walks and going up and down stairs, activities that require range of movement, stamina, and muscle strength 14 . Activities of daily living evaluate the more severe degrees of limitation within the functional spectrum, and the elderly can undergo a major portion of their functional decline without presenting limitations in relation to these activities 15 . The functional disability prevalences evaluated by activities of daily living are lower than those measured by functional disability. In general, mobility presents an intermediate degree of complexity between activities of daily living and instrumental activities of daily living.

The PNAD 200312 provides the opportunity to assess functional disability by means of seven questions, one of which for activities of daily living and six for mobility. To consider functional 
disability as a progressive process, three measures were used as a functional disability scale. To assess the degree of severity of functional disability, the same criteria were used as those for Parahyba et al. 15,16 for the 1998 PNAD. Functional disability was classified as follows: mild (difficulty in walking approximately one kilometer), moderate (difficulty in walking 100 meters), and severe (difficulty in eating, bathing, or going to the bathroom).

Individuals were classified as presenting functional disability when they reported not being able to perform these activities or were able to do so with minor or major difficulty. The elderly who reported not having any difficulty were classified as free of functional disability. Importantly, individuals who reported being incapable of (or who presented major difficulty in) eating, bathing, or going to the bathroom were not included in the questions related to mobility. Thus, all the missing cases $(2,268)$ for the variables related to difficulty in walking one kilometer and 100 meters were classified as presenting functional disability. According to the classification used in this study, a single individual might present different levels of disability, that is, the disability categories are not mutually exclusive. One individual can present what is considered both a "mild" and "moderate" disability, for example, if an individual is not able to walk one kilometer, he is classified as having "mild" disability, and if the same individual has great difficulty in walking 100 meters, he is also classified as having "moderate" disability.

Mortality data were obtained from the life table published by the Instituto Brasileiro de Geografia e Estatística [IBGE, Brazilian Institute of Geography and Statistics] 17 for the year 2003.

Data on prevalence rates for mild, moderate, and severe functional disability were processed with SPSS version 13.0 (SPSS Inc., Chicago, USA).

\section{Method}

Healthy life expectancy was estimated using the method proposed by Sullivan ${ }^{18}$, combining the life table with current population mortality experience in 2003, and the functional disability prevalences in the population during the same period. Thus, the number of years to be lived with functional disability is estimated by applying the functional disability prevalence to the personyears derived from the period life table. The main advantage of the Sullivan method for monitoring trends in healthy life expectancy is that only cross-sectional data are necessary.
Life expectancy with functional disability $\left(\mathrm{LEFD}_{\mathrm{X}}\right)$ is defined as:

$$
\operatorname{LEFD}_{X}=\frac{\sum\left({ }_{n} \pi_{x}\right)_{n} L_{x}}{l_{x}}
$$

Where $\mathrm{LEFD}_{\mathrm{x}}$ : life expectancy with functional disability, which corresponds to the mean number of years to be lived with functional disability starting at age $x ;{ }_{n} \pi_{x}$ : proportion of persons with functional disability in the age group $x$ to $x+n$; ${ }_{n} L_{x}$ : person-years lived from $x$ to $x+n$, which corresponds to the total years lived by the cohort during the interval; $l_{\mathrm{x}}$ : probability of surviving until age $x$.

The survival tables were constructed separately for each sex and level of functional disability. The number of years lived within each age bracket in the life table was distributed according to the prevalence of mild, moderate, and severe functional disability in each specific age group, presupposing the same life table for all three groups of functional disability, that is, non-differential mortality according to types of functional disability.

\section{Results}

Functional disability prevalences decreased with the increase in severity (Table 1). Regardless of the measure employed, the functional disability prevalences increased with age and were higher among women as compared to men in all the age groups analyzed. With increasing age, and in both sexes, the severe functional disability prevalence was the one that increased the most, as compared to mild and moderate. In the case of men, the prevalence for mild functional disability varied from $21.6 \%$ in the $60-64$-year group to $66.1 \%$ in the 80 -and-over group, corresponding to a prevalence 2.1 greater in the latter age group. As for moderate and severe functional disability, in the last age group as compared to the first (60-64 years), the figures increased 3.9 times (from $8.8 \%$ to $43.4 \%$ ) and 4.1 times (from $5.8 \%$ to $29.7 \%$ ), respectively. For women, the rates increased in the oldest age bracket as compared to the 60-64-year group, by 2.1 times (from $37.8 \%$ to $79.6 \%$ ), 2.8 times (14.9\% to $56.2 \%$ ), and 3.6 times ( $7.8 \%$ to $36.1 \%$ ) for mild, moderate, and severe disability, respectively.

For life expectancy in 2003, upon reaching 60 years of age, average life expectancy in men was 19 years, $39 \%$ of which with mild functional disability, $21 \%$ with moderate functional disability, and $14 \%$ with severe functional disability (Table 2). Considering mild functional disability, at age 60, the time free of disability is 11.7 years (19.1-7.4), 
Prevalence of functional disability in the 60-year and older population according to degree of severity, by sex and age group. Brazil, 2003

\begin{tabular}{|c|c|c|c|c|c|c|}
\hline \multirow[t]{3}{*}{ Age group (years) } & \multicolumn{6}{|c|}{ Level of functional disability (\%) } \\
\hline & \multicolumn{3}{|c|}{ Men } & \multicolumn{3}{|c|}{ Women } \\
\hline & Mild & Moderate & Severe & Mild & Moderate & Severe \\
\hline $60-64$ & 21.6 & 8.8 & 5.8 & 37.8 & 14.9 & 7.8 \\
\hline $65-69$ & 29.6 & 13.8 & 7.8 & 45.6 & 19.8 & 10.3 \\
\hline $70-74$ & 38.1 & 17.7 & 12.2 & 52.2 & 25.6 & 13.9 \\
\hline $75-79$ & 45.4 & 25.8 & 16.6 & 63.8 & 37.5 & 20.4 \\
\hline$\geq 80$ & 66.1 & 43.4 & 29.7 & 79.6 & 56.2 & 36.1 \\
\hline
\end{tabular}

Source: 2003 National Sample Household Survey (PNAD 2003) 12.

Table 2

Estimated life expectancy with functional disability for the 60-year and older population by degree of severity, age, and sex. Brazil, 2003.

\begin{tabular}{|c|c|c|c|c|c|c|c|c|}
\hline \multirow[t]{2}{*}{ Sex } & \multirow[t]{2}{*}{$\begin{array}{c}\text { Age } \\
\text { (years) }\end{array}$} & \multirow[t]{2}{*}{$\begin{array}{c}\text { Life } \\
\text { expectancy }\end{array}$} & \multicolumn{3}{|c|}{ Life expectancy with functional disability } & \multicolumn{3}{|c|}{$\begin{array}{l}\text { Proportion of years of life with } \\
\text { functional disability }\end{array}$} \\
\hline & & & Mild & Moderate & Severe & Mild & Moderate & Severe \\
\hline \multirow[t]{3}{*}{ Men } & 60 & 19.1 & 7.4 & 4.0 & 2.6 & 38.9 & 21.0 & 13.9 \\
\hline & 70 & 13.1 & 6.7 & 3.9 & 2.6 & 51.0 & 29.8 & 20.2 \\
\hline & 80 & 8.8 & 5.8 & 3.8 & 2.6 & 66.1 & 43.4 & 29.7 \\
\hline \multirow[t]{3}{*}{ Women } & 60 & 22.1 & 12.4 & 6.9 & 4.0 & 56.3 & 31.5 & 18.3 \\
\hline & 70 & 15.0 & 10.1 & 6.3 & 3.8 & 67.1 & 41.9 & 25.2 \\
\hline & 80 & 9.6 & 7.7 & 5.4 & 3.5 & 79.6 & 56.2 & 36.1 \\
\hline
\end{tabular}

Source: 2003 National Sample Household Survey (PNAD 2003) 12 and Brazilian Institute of Geography and Statistics (IBGE), 200517.

corresponding to $61.3 \%$ of the total time from that age onward. Considering moderate functional disability, the respective figures are 15.1 years (19.1-4.0) and 79.1\%. For severe functional disability, the figures are 16.5 years (19.1-2.6) and $86.4 \%$, respectively. At this same age, life expectancy for women was 22.1 years, $56.3 \%$ of which with mild functional disability, $31.5 \%$ with moderate, and $18.3 \%$ with severe. Also, in women aged 60 years, considering mild and functional disability, the number and proportion free of disability was 9.7 years and $43.9 \%$ of the time from this age onward, respectively. For the moderate level, the figures were 15.2 years and $68.8 \%$, respectively. For severe functional disability, the figures were 18.1 years and $81.9 \%$, respectively.

As for trends in life expectancy based on the three levels of disability. The number of years of life with disability starting at 60 years as compared to 80 years was greater for mild functional disability: 7.4 versus 5.8 years for men (reduction of $22 \%$ ), and 12.4 versus 7.7 years for women (reduction of 38\%). These reductions were $5 \%$ and $22 \%$ for men and women, respectively, based on moderate disability (changes from 4.0 to 3.8 years for men, and from 6.9 to 5.5 years for women). For severe functional disability, especially for elderly males, the number of years with disability remained virtually constant (2.6 years at each age), while for women there was a $12.5 \%$ reduction (from 4.0 to 3.5 years). Thus, the total years of life at each age, some 2.6 years for men, and around 3.5 years for women, will be spent with difficulty or dependency in performing activities of daily living, eating, bathing, and going to the bathroom, regardless of the total number of additional years at each age.

While Brazilian women live longer than Brazilian men, the proportion of years to be lived free of mild, moderate, or severe functional disabil- 
ity is lower. Therefore, women present a higher number of years with functional disability, which can be observed in all ages analyzed, regardless of whether one is evaluating mild, moderate, or severe functional disability (Table 3 ). As occurred with total life expectancy, the sex differences in the number of years of life with functional disability decrease with age, which can be observed for the different levels of disability. The largest differences between the sexes at each age are for moderate functional disability, and the smallest for mild functional disability. This difference is highest at 60 years of age, when the number of years with moderate functional disability for women is $73 \%$ greater than for men, and is smallest at 80 , when the proportion of years with mild disability for women is $33 \%$ greater than for men.

Analyzing the differences in functional disability levels, given sex and exact age, the ratios are smaller between time with moderate versus severe functional disability, as compared to mild versus severe (Table 4). For women, the largest difference occurs at 60 years, comparing the mild and severe forms, when the ratio is 3:1, indicating that the proportion of years with mild functional disability surpasses the proportion with severe functional disability by $210 \%$. Meanwhile, the smallest difference occurs at 80 years, comparing moderate and severe functional disability, with a ratio of 1:1.56, indicating that the period with moderate functional disability is $56 \%$ greater than for severe disability.

For men, the largest difference is also at 60 years, when life expectancy with mild functional disability is $180 \%$ greater than for severe disability, while the smallest difference is at 80 years, when life expectancy with moderate functional disability is $46 \%$ greater than for severe.

\section{Discussion}

This study attempted to estimate and compare life expectancies for different degrees of functional disability. Generally, studies that estimate healthy life expectancy in relation to disability lack uniformity. They use different forms of estimation, with distinct indicators and scales, which hinders subsequent comparisons. These differences can be partially attributed to the form in which the information is available and to each researcher's objective. The present study attempted to work with three levels of functional disability, considering their progressive nature, using data from a survey which is not directed specifically to assessing functional disability in the elderly population, but which provides nationally representative data. The aim was thus to
Table 3

Ratios between estimated years of life with functional disability (women versus men) in the population 60 years and older, by degree of severity and age. Brazil, 2003.

\begin{tabular}{lcccc}
\hline Age (years) & $\begin{array}{c}\text { Total life } \\
\text { expectancy }\end{array}$ & \multicolumn{2}{c}{ Life expectancy with functional disability } \\
& Mild & Moderate & Severe \\
\hline 60 & 1.16 & 1.68 & 1.73 & 1.54 \\
80 & 1.15 & 1.51 & 1.62 & 1.46 \\
\hline
\end{tabular}

Source: 2003 National Sample Household Survey (PNAD 2003) 12 and Brazilian Institute of Geography and Statistics (IBGE), 200517.

Table 4

Ratios between estimated years of life with functional disability for the population 60 years and older, according to degree of severity, by age and gender. Brazil, 2003.

\begin{tabular}{llccc}
\hline Age (years) & \multicolumn{2}{c}{ Ratios between life expectancies with functional disability } \\
Men & Women \\
& Mild/Severe & Moderate/Severe & Mild/Severe & Moderate/Severe \\
\hline 60 & 2.85 & 1.54 & 3.10 & 1.73 \\
70 & 2.58 & 1.50 & 2.66 & 1.66 \\
80 & 2.23 & 1.46 & 2.20 & 1.54 \\
\hline
\end{tabular}

Source: 2003 National Sample Household Survey (PNAD 2003) 12 and Brazilian Institute of Geography and Statistics (IBGE), 200517.

understand how sensitive the estimates were for the given level of disability.

The resulting differences between the number of years lived with mild, moderate, and severe functional disability were already expected. After all, depending on the indicator used to measure health or functional disability, the prevalence can vary considerably 13 . In the present study, the less inclusive the indicator, the smaller the prevalence of disability. Suffice it to recall that an individual who experiences difficulty or is unable to walk one kilometer may perfectly well not experience difficulty in eating, bathing, or going to the bathroom or even walking 100 meters. Thus, the mild forms of functional disability show a higher prevalence in the elderly population and thus total more years of life with this health condition. However, interestingly, the difference between the number of years with moderate versus severe functional disability is considerably smaller than between the two extreme forms (mild versus severe). Even so, there are no cases in either men or women in which the difference is negligible. In 
other words, the degree of functional disability remains relevant even when broken down into three levels of severity.

In 2003, elderly women showed higher life expectancy. However, as compared to men, they showed a smaller proportion of years free of functional disability, regardless of whether it was classified as mild, moderate, or severe. Thus, while on the one hand, as compared to elderly men, women live longer, on the other they tend to spend more years with functional disability, which is observed at all the ages analyzed, in both relative and absolute terms. Even if the measurement of functional disability varies between studies, hindering comparisons, the results of the present study corroborate prior work highlighting women's disadvantage 7,8,9,11,19.

The results show that with advancing age, the differences between the sexes decreases in terms of life expectancy and the number of years of life with mild, moderate, and severe functional disability. This trend indicates that the "oldest old" are more homogeneous in terms of health conditions, i.e., that the effect of selectivity is more pronounced in younger elders.

Meanwhile, in absolute terms, life expectancy with severe functional disability did not show large variations with advancing age. This trend suggests there may be fixed number of years in late life in which the needs for basic care are vital. Indeed, the simple use of prevalence measures for severe functional disability does not allow observing this type of behavior, since the prevalences increase with age, which reinforces the importance of healthy life expectancy estimates for studying the elderly population.

However, some limitations in this study should be emphasized. First, the estimates use the same life table for the various levels of functional disability, considering that mortality would behave equally for the same levels, which may not necessarily happen. However, obtaining mortality data disaggregated by levels of functional disability was not an option. In addition, a previous study with elderly Brazilian women 15 showed that despite presenting different magnitudes, the distribution of these three indicators of functional disability is relatively uniform in relation to socio-demographic indicators. This type of behavior suggests that the same life table can be used for different levels of functional disability.

Another limitation is that the use of periodspecific data fails to incorporate possible changes in relation to improvements in health conditions and mortality rates in the population. However, this problem is inherent not to the method, but to the construction of the period life tables. Importantly, the Sullivan method does not allow to assess transitions from one health condition to another, for example the return of a functionally disabled individual to functional disability-free status, which is only analyzed by the multi-state model, with the use of longitudinal incidence data. However, prior studies have demonstrated that if there are no sudden alterations in prevalence or mortality rates, the Sullivan method is quite reliable for this type of analysis 20 . It also appears reasonable to suppose that with increasing age, the return to disability-free status is less likely, that is, that the use of multi-state models would bring relatively insignificant gains. Thus, the estimates performed here can be viewed as reflecting the reality of the Brazilian elderly population in 2003.

Finally, to the extent that the current study presents information on the proportion of years of life with and without functional disability, it provides backing for estimating the demand for health care and interventions in the elderly population, pointing to the need to invest in prevention in order to expand disability-free life expectancy. By considering functional disability as a progressive process, we have sought to provide information on the number of years of life with mild, moderate, and severe functional disability, which can support public policies that use prevention to decrease the number of years of life with various levels of functional disability. That is, based on the analysis of these estimates, it is possible to design and implement policies and measures capable of aiding both prevention (when the problem has still not emerged or can be considered mild) and phases where rehabilitation and support are essential. 


\section{Resumo}

Informações sobre o número de anos a serem vividos com incapacidade funcional possibilitam direcionar políticas públicas que visem a diminuir o número de anos nestas condições. Desagregadas segundo diferentes niveis de incapacidade, podem ensejar o desenho e implementação de ações mais específicas e eficazes. $O$ objetivo deste estudo foi medir a expectativa de vida livre de e com incapacidade funcional para os idosos brasileiros em 2003, por sexo e idade, utilizando diferentes níveis de incapacidade funcional. Empregou-se o método de Sullivan, combinando a tábua de vida e as prevalências de incapacidade funcional. Foram utilizadas as tábuas de vida publicadas pelo Instituto Brasileiro de Geografia e Estatística e as prevalências de incapacidade da Pesquisa Nacional por Amostra de Domicílios. Os principais resultados indicam que, aos 60 anos, a expectativa de vida dos homens era de 19 anos, 39\% com incapacidade funcional leve, 21\% com incapacidade moderada e $14 \%$ com incapacidade funcional grave. Nessa mesma idade, a expectativa de vida das mulheres era de 22 anos (56\%, 32\% e 18\% com incapacidades funcionais leve, moderada e grave, respectivamente).

Idoso; Expectativa de Vida Ativa; Idoso Débil

\section{References}

1. Manton KG, Stallard E. Recent trends in mortality analysis. Orlando: Academic Press; 1984.

2. Jagger C. Health expectancy calculation by the Sullivan Method: a practical guide. Tokyo: Nihon University Population Research Institute; 1999. (NUPRI Research Paper, 68).

3. Robine JM, Romieu I, Cambois E. Health expectancy indicators. Bull World Health Organ 1999; 77:181-5.

4. Bone MR. International efforts to measure health expectancy. J Epidemiol Community Health 1992; 46:555-8.

5. Paschoal SMP. Autonomia e independência. In: Papaléo-Netto M, organizador. Gerontologia: a velhice e o envelhecimento em visão globalizada. São Paulo: Editora Atheneu; 2002. p. 311-23.

6. Ramos LR. A mudança de paradigma na saúde e o conceito de capacidade funcional. In: Ramos LR, Toniolo-Neto J, organizadores. Guia de geriatria e gerontologia. São Paulo: Editora Manole; 2005. p. 1-7.

7. Agree EM. The influence of personal care and assistive devices on the measurement of disability. Soc Sci Med 1999; 48:427-43.

\section{Contributors}

The authors participated equally to all stages of the work.
8. Baptista DBDA. Idosos no município de São Paulo: expectativa de vida ativa e perfis multidimensionais de incapacidade a partir da SABE [Masters Thesis]. Belo Horizonte: Centro de Desenvolvimento e Planejamento Regional, Universidade Federal de Minas Gerais; 2003.

9. Camargos MCS, Perpétuo IHO, Machado CJ. Expectativa de vida com incapacidade funcional em idosos em São Paulo, Brasil. Rev Panam Salud Pública 2005; 17:379-86.

10. Romero DE, Leite IC, Szwarcwald CL. Healthy life expectancy in Brazil: applying the Sullivan method. Cad Saúde Pública 2005; 21 Suppl 1:S7-18.

11. Camargos MCS, Machado CJ, Rodrigues RN. Disability life expectancy for elderly, city of São Paulo, Brazil, 2000: gender and educational differences. J Biosoc Sci 2006; 39:455-63.

12. Instituto Brasileiro de Geografia e Estatística. Pesquisa Nacional por Amostra de Domicílios, 2003. Rio de Janeiro: Instituto Brasileiro de Geografia e Estatística; 2003.

13. Jette AL. How measurement techniques influence estimates of disability in older populations. Soc Sci Med 1994; 38:937-42. 
14. Guralnik JM, Fried LP, Salive ME. Disability as a public health outcome in the aging population. Annu Rev Public Health 1996; 17:25-46.

15. Parahyba MI, Veras R, Melzer D. Incapacidade funcional entre as mulheres idosas no Brasil. Rev Saúde Pública 2005; 39:383-91.

16. Parahyba MI, Melzer D. Profile of disability in older people in Brazil: results of the PNAD survey. In: Encontro Nacional de Estudos Populacionais. http://www.abep.nepo.unicamp.br/docs/anais/ pdf/2002/Com_ENV_ST31_Parahyba_texto.pdf (accessed on 24/Jan/2006).
17. Instituto Brasileiro de Geografia e Estatística. Tábuas completas de mortalidade - 2003. http:// www.ibge.gov.br (accessed on 25/Nov/2005).

18. Sullivan DF. A single index of mortality and morbidity. HSMHA Health Rep 1971; 86:347-54.

19. Zimmer Z. Active life expectancy and functional limitations among older Cambodians: results from a 2004 survey. New York: Population Council; 2005. (Working Papers, 201).

20. Mathers CD, Robine JM. How good is Sullivan's method for monitoring changes in population health expectancies? J Epidemiol Community Health 1997; 51:80-6.

Submitted on $26 /$ Oct/2006

Final version resubmitted on 28/Jun/2007

Approved on 07/Aug/2007 